\title{
Modelo de acumulación colombiano. Génesis del conflicto armado*
}

\author{
Andrés Leaño**
}

\section{Resumen}

El presente artículo plantea como tesis que la génesis del conflicto armado colombiano se debió al modelo de acumulación y reproducción del capital basado en el despojo de tierras a colonos y campesinos.

Este conflicto entre fuerzas tenía un fuerte interés económico que consistía en controlar tierras geoestratégicas. El despojo de tierras produjo un desplazamiento de aproximadamente dos millones de personas, cuyas tierras fueron tomadas por la oligarquía, que presenta como característica central la concentración de la propiedad de las tierras en pocas manos. Se trata de la aplicación del modelo de acumulación por desposesión, que según Harvey (2007) comprende la mercantilización y privatización de la tierra y la expulsión forzosa de la población.

Todo ello acompañado por una crisis de hegemonía de la clase dirigente -Partido Conservador y Partido Liberal-, que apelándonos a Gramsci (2011) se produce por que dicha clase fracasó en consolidar el consenso de masas generando un periodo de violencia. De igual modo citando a Gramsci, se

* Artículo recibido el 11 de Marzo de 2015. Aceptado el 9 de Abril de 2015.

** Andrés Leaño es Trabajador social egresado de la Universidad Industrial de Santander (Colombia), Especialista en Pedagogía para el Aprendizaje Autónomo de la Universidad Nacional Abierta a Distancia (Colombia); actualmente becario de la Maestría en Políticas de Desarrollo Universidad Nacional de la Plata (Argentina).

Correo electrónico: jandres1386@gmail.com 
analizan las relaciones de fuerza entre las clases sociales; como consecuencia de esto, las urbes concentraron gran población desplazada, lo que favoreció la explotación de la naciente clase obrera a raíz de la plusvalía, de este modo, la naciente industria nacional se vio beneficiada. Todo este contexto auguró el surgimiento de la guerrilla de las FARC.

\section{Palabras clave}

Modelo de Acumulación - Desposesión - Crisis de hegemonía.

\section{Abstract}

This article presents the genesis of the Colombian armed conflict, the model of accumulation and reproduction of capital based on the dispossession of land.

This conflict between forces, had a strong economic interest in controlling Geo-strategic land; land dispossession was a shift of about two million people, these lands were taken by the oligarchy that concentrated ownership of land in a few hands, is the application of the model of accumulation by dispossession that according to (Harvey, 2007) comprises commodification and privatization of land and the forced expulsion of population.

All this he accompanied by a crisis of hegemony of the ruling class (Conservative Party and Liberal Party) that based on Gramsci (2011) is produced by such failure class consolidate consensus mass generating a period of violence, likewise, quoting Gramsci, the balance of power between social classes is analyzed; as a result, the cities concentrated large displaced population which favored the exploitation of the emerging working class as a result of surplus value, the nascent domestic industry was benefited, all aided the emergence of the guerrilla FARC.

\section{Keywords}

Accumulation Model - Dispossession - Crisis of hegemony. 
El conflicto armado colombiano tiene sus orígenes en el siglo XIX y resulta difícil establecerlos; sin embargo, desde el 4 de septiembre de 2012, se negocia en La Habana, Cuba, una paz estable que le ponga fin al conflicto. Se lo conoce como el "Acuerdo General para la terminación del conflicto y la construcción de una paz estable y duradera" ${ }^{1}$ que contiene 5 puntos que actualmente se discuten, estos son:

1. Política de desarrollo agrario integral: acuerdo

2. Participación política: acuerdo

3. Fin del conflicto: último tema

4. Solución al problema de las drogas ilícitas: acuerdo

5. Víctimas: conversaciones

En este escrito plantearemos la tesis del conflicto armado como consecuencia del modelo de acumulación colombiano. El término modelo de acumulación hace referencia a "un recorte espacio-temporal del proceso de reproducción ampliada del capital en el cual se observan un conjunto de relaciones sociales regulares que interactúan de modo relativamente coherente entre sí durante un período determinado, relaciones ligadas a tres núcleos constitutivos fundamentales: las políticas económicas, las variables económicas y las fracciones de clases" (Varesi, 2013: 36).

Este modelo de acumulación contienen factores que Basualdo (2007) describe como fundamentales para que exista: la regularidad de su evolución y el orden de prelación entre las variables económicas, que favorecen la dominación de capital como control de la fuerza de trabajo, lo cual genera fricción entre las fracciones de clases, porque el proyecto hegemónico del capital no es el mismo que poseía la burocracia que anteriormente estaba en el poder.

\footnotetext{
${ }^{1}$ Ver: https://www.mesadeconversaciones.com.co/sites/default/files/AcuerdoGeneralTerminacionConflicto.pdf
} 
Gráfico 1. Esquema conceptual

Relación entre régimen y modelo acumulación.

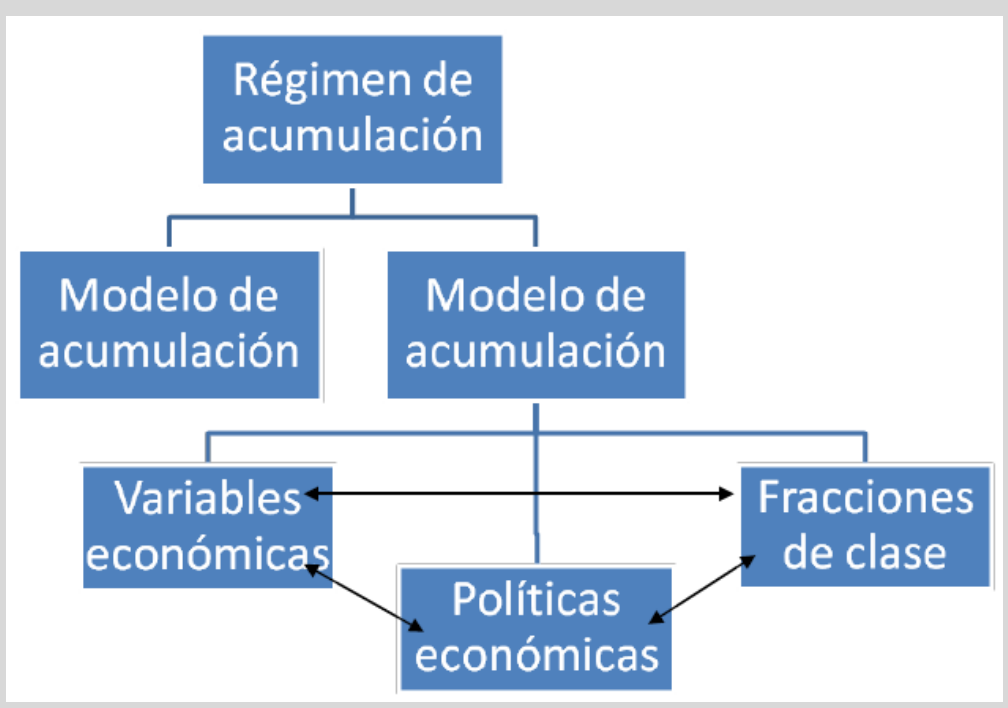

Tomado de: Varesi, 2013. Modelo de acumulación y hegemonía en la Argentina postconvertibilidad, 2002-2008.

En la década de 1930, las luchas entre el Partido Conservador y las ligas campesinas con asiento en el Partido Liberal y algunos sectores del Partido Comunista Colombiano, condujeron a la firma de la Ley 200 de 1936, que garantizaba la inversión de los bienes públicos -tierras- sin cultivar para ser parceladas a los campesinos sin tierras. Dicha Ley fue vetada y cambiada por la Ley 100 de 1944, incentivando la violencia entre sectores del campesinado y terratenientes con el apoyo del Partido Conservador. La estructura socioeconómica de la época estaba en crisis, la caída en los precios internacionales del café afectó los tributos, ya que era la mayor exportación del país. Sumado a esto la dificultad de comercializar con Europa debido a la II Guerra Mundial fueron motivos de la descapitalización del Estado cuyas acciones fueron devaluar la moneda y aplicar una política proteccionista, lo que favoreció a la burguesía cafetera -se crea el Fondo Nacional del Café- y a la burguesía industrial (Pécaut, 2001).

En 1946 el Partido Conservador gana las elecciones y el conflicto va en aumento; algunos historiadores ${ }^{2}$ y sociólogos ${ }^{3}$ lo describen como el inicio del periodo de la violencia bipartidista, en el cual los grandes frentes de poder buscan consolidarse como potencias políticas regionales a cualquier precio, presentándose

\footnotetext{
${ }^{2}$ Sáenz Rovner, Eduardo. Colombia años 50: Industriales, política y diplomacia.

${ }^{3}$ Fals Borda, Orlando. La violencia en Colombia. Editorial Taurus, 2005.
} 
...una ausencia de expresión política legal, legítima y consensual, por el contrario, debe presionar a favor de sus intereses a diversos partidos, instituciones y tendencias de pensamiento o en apelar recurrentemente a la quiebra de la legalidad constitucional, cuando sus valores se ven fuertemente afectados (Villarreal, 1985: 23).

Hablamos de los partidos hegemónicos de la época, el Partido Conservador y el Partido Liberal.

A principios de 1948, la violencia continúa creciendo. El 27 de febrero, el líder Jorge Eliecer Gaitán organizó una gran manifestación contra la violencia y la persecución política por parte del gobierno conservador de Mariano Ospina Pérez, que se conoció como "la marcha del silencio". 41 días más tarde, el viernes 9 de abril, durante la Conferencia Panamericana que tuvo lugar en Bogotá para discutir el diseño económico entre los Estados Unidos y los países periféricos de América Latina, fue asesinado Jorge Eliecer Gaitán, caudillo liberal y candidato a la presidencia, lo que desencadenó revueltas en la mayoría de las regiones de Colombia. En Bogotá se conoció como el Bogotazo y en regiones como los Llanos Orientales fue el insumo para la conformación de las guerrillas Orientales con fuerte influencia liberal, dirigidas por Guadalupe Salcedo.

Luego del Bogotazo, el Partido Conservador y el Liberal comprenden que el conflicto terminó por consolidar un empate hegemónico, ¿qué se conoce en el plano político como empate hegemónico? Según Portantiero, (1973: 8) "cada uno de los grupos tiene suficiente energía como para vetar los proyectos elaborados por los otros, pero ninguno lograr reunir las fuerzas necesarias para dirigir el país como les gustaría", lo que permitió establecer el Frente Nacional como una coalición política y electoral entre Conservadores y Liberales para la sucesión de periodos presidenciales que perduró de 1958 a 1974.

Puesto en marcha el Frente Nacional, la violencia no cede, inicia un cambio de "enemigo" por parte del gobierno hacia la organización comunista y sectores radicales liberales. En el plano internacional se desarrolla la guerra fría.

Cuadro 1. Presidentes de Colombia del Frente Nacional

\begin{tabular}{|c|c|c|c|c|}
\hline $\begin{array}{l}\text { Partido } \\
\text { Político }\end{array}$ & \multicolumn{2}{|c|}{ Nombre } & $\begin{array}{c}\text { Periodo } \\
\text { Presidencial }\end{array}$ & $\begin{array}{c}\text { Programa de } \\
\text { Gobierno }\end{array}$ \\
\hline Liberal & $\begin{array}{l}\text { Alberto } \\
\text { Camargo }\end{array}$ & Lleras & 1958-1962 & $\begin{array}{l}\text { "El Gobierno de la } \\
\text { Restauración" }\end{array}$ \\
\hline Conservador & $\begin{array}{l}\text { Guillermo } \\
\text { Valencia }\end{array}$ & León & $1962-1966$ & $\begin{array}{l}\text { "El Gobierno de la } \\
\text { Pacificación" }\end{array}$ \\
\hline Liberal & $\begin{array}{c}\text { Carlos } \\
\text { Restrepo }\end{array}$ & Lleras & $1966-1970$ & $\begin{array}{l}\text { "El Gobierno de la } \\
\text { modernización }\end{array}$ \\
\hline
\end{tabular}




\begin{tabular}{|c|c|l|l|}
\hline & & & económica" \\
\hline Conservador & $\begin{array}{c}\text { Misael Pastrana } \\
\text { Borrero }\end{array}$ & $1970-1974$ & $\begin{array}{c}\text { "El Gobierno de las } \\
\text { cuatro estrategias" }\end{array}$ \\
\hline
\end{tabular}

Fuente: Elaboración propia.

Las principales fuentes de influencia hegemónicamente conservadoras estaban en regiones agrarias en el occidente del país, entre las que se destacan regiones como: Quindío, Sumapaz, el sur del Tolima y Cauca, mientras que los liberales influían desde el norte hasta el oriente y sur.

Gráfico 2. Mapa de conservadores y liberales Periodo de la Violencia.

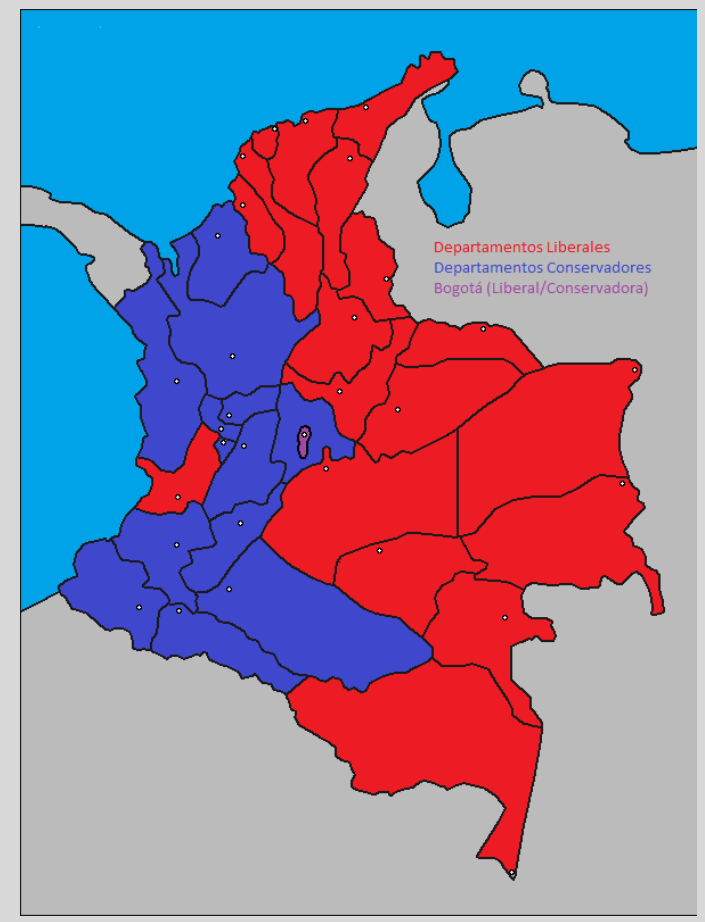

Fuente: “La modernización en Colombia: los años de Laureano Gómez, 1889-1965". Ed. Universidad de Antioquia: 2006.

Según Viera y Alape (1985), el fenómeno ha sido llamado "la violencia en Colombia" y tenía, principalmente, un origen político; sin embargo, planteamos que existía un fuerte interés económico para el control de tierras geoestratégicas: el despojo de tierras produjo un desplazamiento de aproximadamente dos millones de personas a causa de 
las fuerzas liberales (Guerrillas Liberales) y fuerzas conservadoras (Chulavitas). Estas tierras fueron tomadas por la oligarquía, concentrando la propiedad de las tierras en pocas manos, que es la aplicación del modelo de acumulación y reproducción del capital basado en el despojo de tierras a los colonos y campesinos. El despojo de estas tierras tenía varias finalidades: como tierras para la ganadería, la minería y los proyectos agroindustriales (café y banano).

Según Kalmanovitz,

El efecto directo de la desmovilización puede verse en la creciente reducción del poder de negociación de la mano de obra frente al del capital entre los años 1948 y 1958, período central de la violencia y también marco de crecimiento sostenible económica en que los salarios rurales sufrieron una baja del 15\% (2003: 65).

Estos elementos se constituyeron como positivos para la explotación de los proyectos de agroexportación y mineros que se iniciaban en el país.

Las urbes concentraron gran parte de la población desplazada, lo que favoreció la explotación de la naciente clase obrera a raíz de la plusvalía, la naciente industria nacional se ve beneficiada. Según Vernon,

...entre 1949 y 1953 casi se duplicó el valor de las exportaciones de la conversión de este período en una de las subidas más grandes en la historia económica. Entre 1948 y 1952 el porcentaje de formación de capital aumentó de 14,2 \% a 28,2 \% (1983: 65).

Mientras tanto, el Estado ${ }^{4}$ colombiano mantenía la crisis de hegemonía,

El contenido es la crisis de hegemonía de la clase dirigente, que se produce porque dicha clase fracasó en alguna empresa política para la cual requirió o impulsó por la fuerza el consenso de las grandes masas (la guerra, por ejemplo), o bien porque vastas masas (especialmente de campesinos y de pequeños burgueses intelectuales) pasaron de golpe de la pasividad a una cierta actividad y plantearon reivindicaciones que en su caótico conjunto constituyen una revolución. Se habla de 'crisis de autoridad' y esto es justamente la crisis de hegemonía, o crisis del Estado en su conjunto (Gramsci, 2011: 63).

Colombia en ese momento era un país fragmentado por hegemonías condicionadas por los partidos políticos, al final

\footnotetext{
${ }^{4}$ Definición de Estado: "Estado es todo complejo de actividades prácticas y teóricas con las cuales la clase dirigente no sólo justifica y mantiene su dominio, sino también logra obtener el consenso activo de los gobernados" (Gramsci, 2011: 95).
} 
...la hegemonía del liberalismo económico; la legitimidad de la democracia parlamentaria; la regla de política de la población por los dos partidos tradicionales del país; la supervivencia del orden oligárquico que sopesar sus grietas y conflictos; la preservación de los latifundios; y el estancamiento de un Estado que sólo establece para diferenciarse de la parte exterior (Pécaut, 2001: 54).

prevaleció sobre la otra, sin embargo, fue el preludio para el surgimiento de la guerrilla más antigua y numerosa de América Latina.

En el año 1949 se produce el surgimiento de las FARC, Fuerzas Armadas Revolucionarias de Colombia, también conocidas en ese entonces como "La Columna Guerrillera", como herederas de las luchas campesinas y liberales en las regiones del sur del Tolima, en especial el municipio de Chaparral.

Estos campesinos, junto con algunos miembros del Partido Comunista Colombiano, partido político en el cual habían prohibido ${ }^{5}$ la militancia, toman las armas. El gobierno nacional, en 1964, arremete de forma violenta contra estos grupos en la conocida operación Marquetalia, con el objetivo militar de eliminar a la guerrilla asentada en el norte y el sur del Tolima con ayuda de los Estados Unidos y su plan LASO (Latin American Security Operation).

Por otra parte, las FARC se basan en los principios e ideales socialistas -con énfasis en la reforma agraria y proyectos antiimperialistas y anticapitalistas- se autoclasifican como movimiento político, social y armado de Colombia.

Gramsci (2003) analiza las relaciones de fuerza entre las clases sociales y distingue diferentes grados:

1. La relación de fuerzas sociales, estrechamente ligadas a la estructura objetiva, independiente de la voluntad de los hombres, permite controlar el grado de realismo y de posibilidades de realización de las diversas ideologías que nacieron en el terreno de las contradicciones que generaron su desarrollo; en el caso de las FARC, su origen campesino, de colonos desposeídos, sin tierras, recoge el inconformismo y los estragos de la violencia, en especial, el causado por el gobierno conservador de la época y sus fuerzas militares. Es de acotar que la mayor parte de la población colombiana vivía en zonas rurales, las que les fueron arrebatadas, se estiman en unas 383000 hectáreas de tierra.

2. La relación de las fuerzas políticas; es decir, la valoración del grado de homogeneidad, autoconciencia y organización alcanzado por los diferentes grupos sociales. En diferentes regiones, campesinos y colonos se alzaron en armas, ejemplo de ello sería en los llanos orientales y sur de Colombia. El éxito de la naciente Guerrilla fue el alto grado de organización para fundir esos

\footnotetext{
${ }^{5}$ Ver: Acto Legislativo Número 6 de 1954.
} 
movimientos en uno solo estructurado, logrando así cohesionar la propuesta guerrillera.

3. Relación de las fuerzas militares: se distingue dos grados: uno militar en sentido estricto y otro político-militar. En el caso de estudio, las FARC siempre han manifestado su voluntad política de paz y la negociación del conflicto armado, prueba de ello serían los 10 intentos fallidos de paz con los gobiernos de turno. En 1982, en la séptima conferencia guerrillera decidieron crear células políticas clandestinas en su estructura político-militar y "combinar todas las formas de lucha". El resultado de ello es la Unión Patriótica (UP) ${ }^{6}$ y su posterior exterminio por parte del Estado.

De acuerdo con todo lo anterior, emerge la idea de que el modelo de acumulación colombiano se da por la acumulación de capital a través de la expropiación de las tierras de los campesinos y la consolidación del poder terrateniente oligárquico, según Harvey (2007), "la acumulación por desposesión", fundamentada desde la perspectiva de Marx a partir del concepto de acumulación primitiva, estaría conformada por los procesos que incluyen la acumulación por desposesión,

Estas prácticas de desposesión comprenden la mercantilización y privatización de la tierra y la expulsión forzosa de poblaciones campesinas; la conversión de formas diversas de derechos de propiedad (comunal, colectiva, estatales, etc.) en derechos exclusivos de propiedad privada; la supresión de los derechos sobre los bienes; la mercantilización de la fuerza de trabajo y la eliminación de los modos de producción y de consumo alternativos (autóctonos); procesos coloniales, neocoloniales e imperiales de apropiación de activos (recursos naturales entre ellos); y por último, la usura, el endeudamiento de la nación y, lo más devastador, el uso del sistema de crédito como medio drástico de acumulación por desposesión (Harvey, 2007: 116).

Por lo tanto, la acción de la clase dominante aceleró el desarrollo del capitalismo, perpetuando el sistema del uso y tenencia de la tierra, entrando en un proceso de "modernización" y desarrollo rural fomentando el desplazamiento de campesinos hacia las urbes, para trabajar como obreros mal remunerados, explotados por el surgimiento de la industria nacional, que, por otra parte, era incapaz de recibir a toda la masa desplazada, creando enormes cinturones de pobreza en la periferia de las capitales departamentales y, peor aún, en las zonas rurales.

\footnotetext{
${ }^{6}$ Unión Patriótica: partido político, propuesta política legal de varios grupos guerrilleros, fundado en $\underline{1985}$ por las FARC y ELN con el apoyo del PCC.
} 


\section{Reflexiones}

Al revisar la historia colombiana y mirarla a la luz de conceptos de autores como Harvey y Gramsci, se logra comprender la debilidad del Estado y sus modificaciones en favor del modelo económico del país; dicha debilidad surge por el empate hegemónico entre las fuerzas políticas del momento -régimen político- el cual alteró el modelo económico, favoreciendo la acumulación de las clases dominantes y el despojo del campesino y del trabajador.

Las relaciones entre Estado, régimen político y modelo económico favorecieron la violencia para la acumulación de capital y el modelo basado en la dominación del territorio y la exclusión de diversos sectores de la población colombiana permite la continuidad del régimen político, donde se alternan en el poder no solo los partidos políticos, sino grupos económicos bajo la dinámica de explotación, acumulación y despojo que generaron diversos movimientos sociales de diferentes vertientes (campesinado, colonos, sindicalistas, estudiantiles etc.) y al mismo tiempo de resistencia, que, ante la ausencia, la debilidad del Estado y el uso de la violencia como mecanismo de dominación, propició el surgimiento de la lucha armada, todo ello en un contexto internacional de lucha y cambio que caracterizaron aquella época.

Tal vez sea tarde para revivir la Ley 200 de 1936, que garantizaba la inversión de los bienes públicos sin cultivar para ser parceladas a los campesinos sin tierras, sin embargo, en la actualidad, ante las amenazas que ejercen los Tratados de Libre Comercio y la globalización, que perjudican de manera exponencial al campesinado, se requiere de una reforma agraria profunda que le devuelva la tierra a los campesinos, deteniendo la inversión extranjera que financia los proyectos agroindustriales y mineros, el cual produjo que Colombia pasara de ser exportador de productos agropecuarios a ser importador.

La participación política termina siendo la esperanza del Estado para su fortalecimiento, que surgiría orientada a garantizar una oportunidad a los diferentes actores; dicho fortalecimiento implica la reciprocidad de la sociedad civil para el aumento de la regulación social por parte del Estado.

Teniendo en cuenta el desconocimiento de lo negociado en La Habana, Cuba, en relación con los cinco temas del acuerdo, se esperan cambios profundos, en especial en la Política de desarrollo agrario y participación política, causantes indirectas del conflicto armado. Este documento termina siendo una visión del conflicto como aporte para la recién creada Comisión Histórica del Conflicto y la importancia de re-escribir la historia y encontrar las causas reales, consecuencias, efectos para el esclarecimiento de la verdad histórica, todo ello en un periodo de consolidación del Acuerdo y de generación de un periodo de posconflicto. 


\section{Bibliografía}

ALAPE, Arturo (1987). El Bogotazo: así fue el 9 de abril. Bogotá, Pluma, 1983. 2a ed.: Bogotá: Planeta.

BASUALDO, Eduardo (2007). Concepto de patrón o régimen de acumulación y conformación estructural de la economía, Documento n¹, Maestría en Economía Política Argentina, Área de Economía y Tecnología de la FLACSO. Disponible en www.flacso.org.ar/economía.

VIEIRA, Gilberto y ALAPE, Arturo Alape (1985) La paz, la violencia: testigos de excepción, $5^{\mathrm{a}}$ ed. Bogotá: Planeta Colombiana.

GRAMSCI, Antonio. (2003). Análisis de situaciones. Relaciones de fuerzas en Notas sobre Maquiavelo, sobre la política y sobre el Estado moderno. Buenos Aires: Nueva Visión.

HARVEY, David. (2007). Breve historia del Neoliberalismo. Madrid: Akal.

HENDERSON, James. (2006). La modernización en Colombia. Los años de Laureano Gómez, 1889-1965. Medellín, Editorial Universidad de Antioquia KALMANOVITZ, Salomón. (2003). Economía y Nación. Una breve historia de Colombia. Bogotá: Norma.

BORDA, Orlando, GUZMÁN, Germán, UMAÑA, Eduardo Luna. (2005). La violencia en Colombia. Lugar: Editorial Taurus.

PÉCAUT, Daniel. (2001). Orden y violencia. Evolución sociopolítica de Colombia entre 1930 y 1953. Bogotá: Norma.

PORTANTIERO, Juan Carlos. (1973). "Clases dominantes y crisis política en la Argentina actual". Ed. La rosa blindad

ROBINSON, J. Cordell. (1976). El movimiento Gaitanista en Colombia. Bogotá: Tercer Mundo.

SÁENZ, Eduardo. Colombia años 50: Industriales, política y diplomacia. Colección Colombia años 50. Volumen 4, Univ. Nacional de Colombia, Sede Bogotá 2002, ISBN 958-701-131-7, 958-701-132-5

VALENCIA, Luis Emiro. (1968). (Ed.). Gaitán. Antología de su pensamiento económico y social. Bogotá: Ediciones Suramérica.

VARESI, Gastón Ángel. (2013). Modelo de acumulación y hegemonía: aportes teóricos para su abordaje conjunto, Capítulo 1 de Modelo de acumulación y hegemonía en la Argentina postconvertibilidad, 2002-2008. Tesis de Doctorado. Doctorado en Ciencias Sociales, FAHCE-UNLP.

VERNON, Lee Fluharty. (1981). La danza de los millones, régimen militar y revolución en Colombia (1930-1956). Bogotá: El Áncora Editores.

VILLARREAL, Juan. (1985). Los hilos sociales del poder, en Crisis de la dictadura Argentina. Buenos Aires: Siglo XXI. 